\title{
EFFECT OF HYDRO-ALCOHOLIC POLY HERBAL FORMULATION ON CARDIAC MARKERS WITH ATHEROGENIC DIET FED ANIMAL MODEL OF OBESITY IN WISTAR RATS
}

\author{
Shokouh Hajighasemi Dastjerdi ${ }^{1}$, Muralidhar.S.Talkad ${ }^{2}{ }^{2}$,Rakesh. $\mathbf{N}^{3}$ \\ ${ }^{1}$ P.G. Department of Pharmacology, Dr Nargund Research Foundation, $2^{\text {nd }}$ main dattatreyanagar, 100 \\ feet ring road, Banashankari $3^{\text {rd }}$ stage, Bangalore -560085 \\ 2*, 3 P.G. Department of Biotechnology, R\&D Centre, Dayananda Sagar University, \\ Kumaraswamy Layout, Bangalore- 560078, India
}

\begin{abstract}
Aim: Pharmacological screening of obesity were planned in response to an atherogenic diet and to estimate the effect of Cyperus Rotundus Linn, Terminalia Arjuna \& Cinnamomum Zeylanicum Nees, on plasma Adiponectin, cardiac function markers, ECG and heart rate in wistar rats. Obesity associated with Cardio vascular properties is rapidly increasing throughout the world. It is generally recognized that natural products with a long history of safety can modulate obesity. Obesity was induced by feed with an atherogenic diet for over a period of 60 days. Methods: The hydro-alcoholic extract of herbal formulation containing Cyperous rotundus, Terminalia arjuna and Cinnamomum zeylanicum was administered orally in dose of $480 \mathrm{mg} / \mathrm{kg}$, p.o (high dose), 360mg/kg p.o (mid dose) and $120 \mathrm{mg} / \mathrm{kg}$ p.o (low dose) was administered, daily body weight, locomotor activity, organ and fat pad weights, plasma adiponectin, renal function and cardiac markers were analyzed.Results: Atherogenic diet induced obesity associated with an altered cardiac biomarkers, Plasma Adiponectin and cardiac parameters (ECG, Heart rate); this may have implications for the progress of obesity related problems and it significantly increased final body weight, fat pad weights, triglycerides (TG), total cholesterol HDL, \& LDL concentration, moreover treatment with Cyperus rotundus poly herbal formulation extract improved obesity and its associated metabolic problems at different levels. Conclusion: Cyperus rotundus linn might be a safe drug on the target organs with no pathological impact since it lowed that extant damage of an Atherogenic diet induced obesity and exhibited a distinct anti-obesity effect.
\end{abstract}

\section{KEY WORDS}

Atherogenic diet, Adiponectin, anti-obesity Cardiac biomarkers, Cyperus rotundus linn Poly herbal formulation, ECG, Heart rate

\section{INTRODUCTION}

Atherosclerosis is a complex disease, involving many cell types and circulating mediators and resulting in an inflammatory state. Atherosclerotic lesions form de novo from focal accumulation of lipoproteins, monocyte derived macrophages, and lymphocytes within the arterial wall. These lesions can develop as early as the second decade of life and progress into clinical disease over time. The formation of plaque in the arterial intima may be due to hyperlipidemia which may include increased serum concentrations of total cholesterol and low density lipoprotein concentration. However, despite recent advances in cardiology, atherosclerosis remains an important medical problem.

Increased oxidative stress, arising from high fat diet appears to play an important role in chronic inflammation responses to hypercholesterolemia atherosclerosis. Cardiac reactive oxygen species has been associated with atherosclerosis development [1] while an atherogenic diet induces superoxide radical production [2] resulting in lipid peroxidation generating more peroxide radical. 
Previous phytochemical studies on C.rotundus revealed the presence of alkaloids, flavonoids, tannins, starch, glycosides and furochromones, and many novel sesquiterpenoids [3- 7]. In Asian countries, the rhizomes of $C$. rotundus, which are used as traditional folk medicines for the treatment of stomach and bowel disorders, and inflammatory diseases, have been widely, investigated [8-10].

C. rotundus is a traditional herbal medicine used widely as analgesic, sedative, antispasmodic, antimalarial, stomach disorders and to relieve diarrhoea [11-12].

The tuber part of $C$. rotundus is one of the oldest known medicinal plants used for the treatment of dysmenorrheal and menstrual irregularities [13-14]. Infusion of this herb has been used in pain, fever, diarrhoea, dysentery, an emmenagogue and other intestinal problems [15].

The atherogenic diet induced a collapse of the erythrocyte antioxidant defense system (significant decrease in superoxide dismutase, catalase and glutathione peroxidase activities). Atherogenic diet also induced an increase in plasma total cholesterol, triglyceride, thiobarbituric acid reactive substances (TBARS), oxidation of low density lipoprotein cholesterol (LDL) and accumulation of foam cells in the aorta a hall mark for atherosclerosis. Administration of the Piper species prevented the collapse of the antioxidant system and the increase of plasma parameters maintaining them towards normality. The Piper species also prevented LDL oxidation by increasing the time (lag time) for its oxidation. The Piper species have significant antioxidant and anti-atherogenic effect against atherogenic diet intoxication [16].

The present investigation were carried out on the hydro-alcoholic extracts of herbal formulation containing Cyperous rotundus, Arjuna bark and Cinnamon bark were found to be very effective in counteracting atherogenic diet induced changes in lipid profile, cardiac biomarkers and metabolic disturbances.

\section{MATERIALS AND METHODS}

Plant extract: Cyperus rotundus tubers powder was obtained from Dr. Shrikar Hiremath, Prof. in Sanskrit ayurveda mahavidyalay, BIJAPUR. Terminalia arjuna bark and Cinnamomum zeylanicum powder obtained from Amruth kesari depot in mamulpet, Bangalore.

Dose selection: In the present study three doses of the hydro-alcoholic extract of herbal formulation containing Cyperous rotundus tubers, Terminalia arjuna bark and Cinnamomum zeylanicum bark, were selected one being the lower dose $(120 \mathrm{mg} / \mathrm{kg})$, mid dose $(360 \mathrm{mg} / \mathrm{kg}$ ) and higher dose $(480 \mathrm{mg} / \mathrm{kg})$ [17]. The doses of extracts were administered per oral route in morning and evening through the study period.

\section{Experimental design:}

Atherogenic diet induced obesity: experimental study was carried out using adult male wister rats weighing between 150-200g. All experimental animals' were maintained under standard lab conditions. The approval of institutional animal ethics committee (IAEC/NCP/87/14) was taken prior to the commencement of the study.

Composition of the atherogenic diet: $1 \%$ cholesterol (s d fine-chem limited ), $0.5 \%$ cholic acid (LOBA CHEME), $5 \%$ lard oil (open market ).the diets were provided in addition to normal pellet chow [18].

The parameters studied were: Body weight: the body weight (gm) was recorded on day 1 and then on alternative days during the study period using an electronic balance.

Locomotor activity: the locomotor activity was recorded on day 60 using open field behavior test apparatus and 30 minutes after the administration of hydro- alcoholic extract of poly herbal formulation to the treatment groups. the apparatus consisted of a circular wooden area of $75 \mathrm{~cm}$ diameter and wall with height of $25 \mathrm{~cm}$. open field test was performed by placing the rat in the center circle and recording the ambulatory activity, the frequency of rearing and grooming for a 5 min test period.

Organ and fat pad weights: the animals were sacrificed by cervical dislocation and then different fat pads (mesenteric, left and right perirenal and uterine fat pads) were removed and weighed. 
Biochemical markers like, LDH, CK-MB, CK-NAC, AST, $A L T$, Urea, Uric acid, Creatinine were studied.

Haemodynamic measurement: Changes in electrical activity of the myocardium were detected by the electrocardiogram (ECG) in lead II (INCO NIVIQURE DIGITAL ECG SYSTEM). All data obtained for each module of the system were analyzed with computer software AmbECG Ver.52 (INCO SOFTWARE).

Adiponectin: the plasma adiponectin was analyzed by using the ELISA kit; it is a sandwich enzyme immunoassay for the in vitro quantitative measurement of rat ADP in plasma.
- Atherogenic diet group showed a significant $(P<0.001)$ increase in body weight (g) When compared to control group.

- Poly herbal extract, Low dose level $1(120 \mathrm{mg} / \mathrm{kg})$ showed a decrease in body weight (g): Less significantly $(\mathrm{P}<0.01)$ when compared to atherogenic diet group.

- Poly herbal formulation Mid dose level $(360 \mathrm{mg} / \mathrm{kg})$ showed a significant decrease $(P<0.001)$ in body weight when compared to Atherogenic diet group

- Poly herbal formulation High dose level $(480 \mathrm{mg} / \mathrm{kg})$ showed a significant decrease $(\mathrm{P}<0.001)$ in body weight when compared to atherogenic diet (fig: 1)

\section{RESULTS AND DISCUSSION}



Fig 1: Effect of hydro-alcoholic extract of poly herbal formulation on body weight.

Results are expressed as mean \pm SEM. ( $n=6)$; Control, $A D=$ atherogenic diet. Low dose, Mid dose, High dose; Data was analyzed by One way ANOVA followed by Dunnett's multiple comparison tests; ${ }^{*} \mathrm{P}<0.05,{ }^{*} * \mathrm{P}<0.01,{ }^{*} * \mathrm{P}<0.001, \mathrm{~ns}=$ non significant.

- Atherogenic diet group showed a significant $(P<0.001)$ increase in serum LDH, CK-NAC, CK-MB, AST, ALT, Urea, Uric acid and Creatinine levels when compared to control group.

- dose level $1(120 \mathrm{mg} / \mathrm{kg})$, hydro alcoholic extract showed an decrease in serum LDH, CK-NAC, CK$M B, A S T, A L T$, urea, uric acid which is significant when compared to atherogenic group.

- dose level $2(360 \mathrm{mg} / \mathrm{kg})$ showed a significant $(P<0.001)$ decrease in serum $C K-M B, C K-N A C$,
AST, ALT, LDH, uric acid, creatinine and Urea when compared to Atherogenic diet group.

- Dose level $3(480 \mathrm{mg} / \mathrm{kg})$ showed a significant $(\mathrm{P}<0.001)$ decrease in serum CK-MB, AST, LDH, uric acid, creatinine and Urea when compared to Atherogenic diet group.

- Dose level 3 showed a significant $(P<0.05)$ decrease in serum ALT levels when compared to Atherogenic group. 
- Dose level 3 showed a non significant decrease in group (Table: 1$)$.

CK-NAC levels when compared to Atherogenic

Table 1: Effect of hydro-alcoholic extract of poly herbal formulation of Cyperus rotundus on biochemical estimations.

\begin{tabular}{|c|c|c|c|c|c|c|c|c|}
\hline Groups & $\operatorname{LDH}(\mathrm{u} / \mathrm{l})$ & $\begin{array}{l}\text { CK- } \\
\text { NAC(u/l) }\end{array}$ & $\begin{array}{l}\text { CK- } \\
M B(u / l)\end{array}$ & $\operatorname{AST}(u / l)$ & $\operatorname{ALT}(u / I)$ & $\begin{array}{l}\text { Urea } \\
\text { (mg/dl) }\end{array}$ & $\begin{array}{l}\text { Uric acid } \\
\text { (mg/dl) }\end{array}$ & $\begin{array}{l}\text { Creatinine } \\
(\mathrm{mg} / \mathrm{dl})\end{array}$ \\
\hline \multirow{2}{*}{ Control } & 234.202 & $239 \pm$ & 140.836 & 31.353 & 33.803 & $33.483 \pm$ & $1.712 \pm$ & 0.554 \\
\hline & \pm 0.795 & 0.708 & \pm 0.864 & \pm 0.111 & \pm 0.061 & 0.489 & 0.014 & \pm 0.010 \\
\hline \multirow{2}{*}{ Atherogenic diet } & 383.753 & 369.545 & 255.218 & 68.126 & 49.704 & $48.633 \pm$ & $4.716 \pm$ & 1.401 \\
\hline & $\pm 0.920^{\mathrm{a}^{* * *}}$ & $\pm 1.089^{\mathrm{a}^{* * *}}$ & $\pm 0.568^{\mathrm{a}^{* * *}}$ & $\pm 0.509^{\mathrm{a}^{* * *}}$ & $\pm 0.180^{\mathrm{a}^{* * *}}$ & $0.302^{\mathrm{a}^{* * *}}$ & $0.032^{\mathrm{a}^{* * *}}$ & $\pm 0.019^{\mathrm{a}^{* * *}}$ \\
\hline$A D+$ Low dose & 360.207 & 326.486 & $229.968 \pm$ & 61.363 & 47.414 & $44.816 \pm$ & $3.700 \pm$ & 1.289 \\
\hline level (120mg/kg) & $\pm 3.038^{b^{* * *}}$ & $\pm 2.905^{b^{* * *}}$ & $2.297^{b^{* * *}}$ & $\pm 1.418^{b^{* *}}$ & $\pm 0.297^{b^{* * *}}$ & $0.366^{b^{* * *}}$ & $0.052^{b^{* * *}}$ & $\pm 0.014^{b^{* * *}}$ \\
\hline$A D+$ Mid dose & 290.568 & 276.483 & 178.184 & 45.812 & $41.328 \pm$ & $38.766 \pm$ & $2.603 \pm$ & 0.888 \\
\hline level $(360 \mathrm{mg} / \mathrm{kg})$ & $\pm 3.569^{b^{* * *}}$ & $\pm 2.652^{b^{* * *}}$ & $\pm 2.761^{b^{* * *}}$ & $\pm 0.863^{b^{* * *}}$ & $0.443^{b^{* *}}$ & $0.523^{b^{* * *}}$ & $0.078^{b^{* * *}}$ & $\pm 0.025^{b^{* * *}}$ \\
\hline AD+ High dose & $258.058 \pm$ & $247.212 \pm$ & 155.401 & $37.978 \pm$ & $36.968 \pm$ & $36.565 \pm$ & $2.145 \pm$ & $0.686 \pm$ \\
\hline level $(480 \mathrm{mg} / \mathrm{kg})$ & $4.960^{b^{* * *}}$ & $3.741^{\text {bns }}$ & $\pm 2.686^{b^{* * *}}$ & $0.896^{b^{* * *}}$ & $0.432^{b^{* *}}$ & $0.294^{b^{* * *}}$ & $0.028^{b^{* * *}}$ & $0.026^{\mathrm{bns}}$ \\
\hline
\end{tabular}

Results are expressed as mean \pm SEM. $(n=6){ }^{*} P<0.05,{ }^{* *} P<0.01,{ }^{* * *} \mathrm{P}<0.001$, $n s=$ non significant; a=compared with vehicle control; $b=$ compared with Atherogenic diet; $A D=$ atherogenic diet; Data was analyzed by one - way ANOVA followed by Dunnett's multiple comparison tests.

\section{Observations in ECG \& Heart Rate:}

- Atherogenic diet group showed an increase in R$\mathrm{R}$ Interval, Q-T Interval non significantly and significant $(P<0.001)$ increase in Heart rate when compared to Control group.

- hydro-alcoholic extract, dose level $3(480 \mathrm{mg} / \mathrm{kg})$ group showed a none significant $(P>0.05)$ decrease in $R-R$ interval and none significant ( $P>0.05)$ Decrease in $Q-T$ interval and none significant $(P>0.05)$ decrease in Heart rate when compared to atherogenic diet group.

- hydro-alcoholic extract, dose level $2(360 \mathrm{mg} / \mathrm{kg})$ group showed a none Significant $(P>0.05)$ decrease in R-R interval and none significant $(P>0.05)$ decrease in $Q-T$ interval and none significant $(P>0.05)$ decrease in Heart rate when compared to atherogenic diet group.

- hydro-alcoholic extract,dose level $1(120 \mathrm{mg} / \mathrm{kg})$ group showed a none significant $(P>0.05)$ decrease in $R-R$ interval and none significant $(P>0.05)$ decrease in $Q-T$ interval and none significant $(P>0.05)$ decrease in Heart rate when compared to atherogenic diet group (Table:2). 
ECG \& Heart:

Table 2: Effect of hydro alcoholic extract of poly herbal formulation of Cyperus rotundus on ECG \& Heart rate

\begin{tabular}{llllll} 
ECG Intervals & Control & Atherogenic diet(AD) & AD+CR -1 (120mg/kg) & $\begin{array}{l}\text { AD+CR-2 } \\
(360 \mathbf{m g} / \mathbf{k g})\end{array}$ & $\begin{array}{l}\text { AD+CR-3 } \\
\text { (480mg/kg) }\end{array}$ \\
\hline R-R Interval & $219 \pm$ & $275 \pm$ & $268.5 \pm$ & $218.5 \pm$ & $193.5 \pm$ \\
Q-T Interval & $112.5 \pm$ & $122.5 \pm$ & $118.5 \pm$ & $112.5 \pm$ & $100 \pm$ \\
(m Sec) & 12.500 & $22.500^{\text {ans }}$ & $18.500^{\text {bns }}$ & $0.500^{\text {bns }}$ & $0.200^{\text {bns }}$ \\
Heart rate & $304 \pm$ & $228 \pm$ & $286 \pm$ & $227 \pm$ & $179.5 \pm$ \\
(BPM) & 75.000 & $42.000^{\text {ans }}$ & $27.000^{\text {bns }}$ & $49.500^{\text {bns }}$ & $14.500^{\text {bns }}$ \\
\hline
\end{tabular}

- Atherogenic diet group showed a significant decrease $(P<0.001)$ in plasma adiponectin value when compared to control group.

- Poly herbal formulation dose level 1 (120mg/kg) extract group showed a significant increase in plasma adiponectin value when compared to atherogenic diet group.

- Poly herbal formulation dose level 2 (360mg/kg) group showed a significant increase value when compared to Atherogenic diet group.

- Poly herbal formulation dose level $3(480 \mathrm{mg} / \mathrm{kg})$ group showed a significant increase in value when compared with atherogenic diet (Table: 3 ).

Table 3: Effect of hydro-alcoholic extract of poly herbal formulation of Cyperus rotundus on plasma Adiponectin value.

\begin{tabular}{ll}
\hline Group & Adiponectin $(\mathrm{ng} / \mathrm{ml})$ \\
\hline Control & $628.012 \pm 0.881$ \\
Atherogenic diet & $577.579 \pm 0.613^{\mathrm{a}^{* * *}}$ \\
AD+dose level 1 & $635.634 \pm 2.301^{\mathrm{bns}}$ \\
AD+dose level 2 & $666.323 \pm 4.041^{\mathrm{b}^{* * *}}$ \\
AD+dose level 3 & $692.983 \pm 3.215^{\mathrm{b}^{* * *}}$ \\
\hline
\end{tabular}

Results are expressed as mean \pm SEM. ( $n=6)$; a=compared with vehicle control, $b=c o m p a r e d$ with Atherogenic diet; $A D=$ atherogenic diet; Data was analyzed by One way ANOVA followed by Dunnett's multiple comparison tests; ${ }^{*} \mathrm{P}<0.05,{ }^{* *} \mathrm{P}<0.01,{ }^{* * *} \mathrm{P}<0.001, \mathrm{~ns}=$ non significant. Histopathological profile:

The liver of control rats showed normal hepatocytes with vesicular nucleus and normal architecture with central vein, hepatic artery, bile duct and portal vein. Hepatocytes showed normal morphology.
The AD group rats fed with atherogenic diet showed severe macro vesicular fatty change in cytoplasm of the liver with nucleus being pushed to one corner of hepatocytes appearing as signet ring shaped cells. There was distortion of hepatic architecture with necrosis in the liver and condensation and reduction in the size of nucleus was observed.

The liver of group 1 rats showed moderate fatty changes and also recovery of hepatocytes.

The group 1 rats showed mild fatty change and recovery from the fatty changes induced in the liver. The group 2 and 3 rats showed recovery from the fatty change and appeared as that of the control rats. The aorta of control rats showed normal tunica layers which include tunica media and tunica adventitia.

Group AD rat aorta showed thinning of tunica media layer and blood cells attached to endothelial layer of tunica media. The aorta of group 1, 2, 3 showed tunica media and tunica adventitia layers as that of control rats.

The heart showed no observable histological changes, in $A D$ group fatty changes induced by atherogenic diet have been overcome by the poly herbal drug in the dose dependent manner. However, the dose 1 of poly herbal drug was not effective in overcoming the fatty changes but dose 2, dose 3 were effective in treating atherogenicity

Increased expression of adhesion molecules in human endothelial cells with atherosclerotic lesions may lead to further recruitment of leukocytes to atherosclerotic sites.transcriptions of adhesion molecules are regulated by NF-KB activation.accumulation of 
oxidative-modified LDL cholestrolwithin plaques is a typical feature of atherosclerosis, which contribute to inflammation in atherosclerosis and its pathogenesis.on the other hand, HDL-cholestrol is anti inflammatory and inhibits the expression of cellular adhesion molecules

[19].

The alcoholic extract of C.rotundus produced gradual and persistent fall in blood pressure and stimulate the respiration.the response of epinephrine and acetylcholine on blood pressure were not altered by the extract, but that of histamine was partially blocked [17].

The cardioprotective effects of Terminalia arjuna has been studied in isoproterenol-induced myocardial ischemia model in rats, rabbits and mice by several authors. In one of the study suggest that the alcoholic extract of the bark powder of Terminalia arjuna in rabbit induces myocardial HSP 72 and augments myocardial endogenous antioxidants, without causing any cellular injury and offered better cardioprotection against oxidative stress associated with myocardial IR injury [20].

Study on the effect of C.zeylanicum (CZ) bark extracts on mean arterial blood pressure of normotensive rats (NR), salt loaded hypertensive rats (SLHR), L-NAME hypertensive rats (LNHR) andspontaneously hypertensive rats (SHR). Immediately after IV adminestration a significant drop of BP was shown in NTR, SLHR and LNHR in a dose dependent manner, the drop in BP was not dose dependent in SHR [21].

Lipid peroxidation in the heart leads to loss of the cellular membrane integrity due to oxidative modification of lipids and proteins that can ultimately lead to cardiac arrhythmias, poor contractility, infarction, cardiac failure or sudden death [22]. The potential mechanism for increased lipid peroxidation in cardiac tissue may be due increased lipid substrate within the myocardium in which can serve as a larger target for oxidation by free radicals $[22,23]$. It is well established that elevated myocardial work and mechanical overload is associated with increased free radical production consequently lipid peroxidation [24]. Mechanical overload-induced increases in muscle oxygen consumption accelerate electron flux through the mitochondria in proportion to the need for ATP. This results in increased electron leakage from the electron transport chain and increased production of superoxide anions [22].

Several mechanisms may contribute to the onset and/ or the progression of renal involvement in experimental obesity among them; lipid peroxidation and oxidative stress have been frequently proposed. HFD induces alteration of renal lipid metabolism by an imbalance between lipogenesis and lipolysis in the kidney, as well as systemic metabolic abnormalities and subsequent renal lipid accumulation and lipid peroxidation leading to renal injury [25]. The accumulation of adipose tissue around the kidneys of obese rats penetrates into the medullary sinuses thus increased intrarenal pressures which may cause damage the renal tissue. Damaged renal tissue acts as sources of ROS and develops lipid peroxidation. An increased lipid peroxidation in the kidney tissue, as well as modification of the circulating LDL/VLDL fraction, is probably involved in the onset of kidney lesions in this normoglycaemic rodent model of obesity [26].

Cardiac tissue of obese rats showed significant high content of GSH compared to normal rats [22], demonstrated similar results, increasing of GSH concentration in cardiac tissue in obese rats in response to free radical formation in an effort to protect cells against oxidative damage [22].

The adaptation of the primary antioxidant defense in the hearts of high-fat-fed animals appeared to be less complete, as indicated by the failure of other antioxidant enzyme activities including GST, GPX and PON 1 to increase in the hearts of animals on the high-fat diet.

In the present study, the anti obesity and cardio vascular properties of hydro-alcoholic extracts of poly herbal formulation containing Cyperus rotundus, Terminalia arjuna \& Cinnamomum zeylanicum was studied using atherogenic diet fed animal model of obesity as they have been reported to bear close resemblance to human obesity.

The same inferences were correlated in this present study suggests that the hydro-alcoholic extract shifts the disturbed lipid profile to the normal thereby counters the effects that would have been followed as secondary effects such as Hypertension, 
Atherosclerosis, stroke etc [23]. Components of Cyperus rotundus have hypocholesterolemic activity, Cyperus rotundus tubers might possess lipophilic properties such as sesquiterpenoids or sterols have lipid-lowering effects, resulting in depression of lipid accumulation. It consequently has anti-atherosclerotic properties [24]. Which would result most notably in increased mitochondrial volume and increased glycolytic enzymes necessitating increased activity of creatine kinase, as this enzyme is responsible for rapidly transferring high-energy phosphate groups from the site of production to the site of use [26].

Since the extracts were found to increase the plasma adiponectin concentration in the experimental animals; they may exert effects through AMPK pathway.

Administration of Cyperus rotundus produces a significant decrease in the activity of CK-NAC, CK-MB and LDH. Our findings showed that obese rats treated with the Cyperus rotundus exhibited significant decreases in LDH, CK-NAC and CK MB activity, The Cyperus rotundus content could prevent the development of atherosclerosis through regulating vascular inflammatory processes in rats fed with an atherogenic diet. The obese rats showed a highly significant increase in the concentration of serum urea, uric acid creatinine, compared with the control group [27].

The oral administration of Cyperus rotundus poly herbal formulation shows that serum concentration of urea, uric acid and Creatinine were significantly decreased. The effect of Cyperus rotundus poly herbal formulation on renal lipid metabolism could serve as a new therapeutic approach, as it counters the renal changes associated with metabolic syndrome [28].

Hence, Cyperus rotundus has beneficial effects on renal function. Although there is still debate on the significance of uric acid as a risk factor for cardiovascular disease, many physicians do consider elevated uric acid to be a component of the metabolic syndrome. There is little support for an independent causal role for serum uric acid in the development of CHD.

However, uric acid may provide useful prognostic information in subjects with hypertensive vascular disease, suggesting that the influence of uric acid on
CHD is explained by the secondary association of it with other risk factors such as dyslipidemia, hyperinsulinaemia and obesity [29].

\section{CONCLUSION}

The oral administration of Cyperus rotundus poly herbal extract provoked therapeutic response that serum concentration of urea, uricacid and Creatinine were significantly decreased.

The Cyperus rotundus poly herbal therapy regained the balance between lipogenesis and lipolysis in the kidney to counteract the obesity-associated renal damage, atherosclerosis \& CHD inflammations

\section{ACKNOWLEDGEMENT}

The authors would like to thank P.G. Department of Pharmacology, Dr Nargund Research Foundation. 2nd main dattatreyanagar, 100feet ring road, Banashankari 3rd stage. Bangalore - 560 085, for the support provided for this research work.

\section{REFERENCE}

1. Heymes, C., Bendall, J. K., Ratajczak, P., Cave, A. C., Samuel, J. L., Hasenfuss, G., Increased myocardial $\mathrm{NADPH}$ oxidase activity in human heart failure. Journal of the American College of Cardiology, 41: 2164-2171, (2003).

2. Riss, J., Décordé, K., Sutra, T., Delage, M., Baccou, J. C., Jouy, N., Phycobiliprotein C-phycocyanin from Spirulina platensis is powerfully responsible for reducing oxidative stress and NADPH oxidase expression induced by an atherogenic diet in hamsters. Journal of Agricultural and Food Chemistry, 55: 7962-7967, (2007).

3. Harborne, JB., Williams, C.A., Wilson, K.L. Flavonoids in leaves and inflorescences of Australian Cyperus species. Phytochemistry, 21: 2491-2507, (1982).

4. Umerie, S.C., Ezeuzo, H.O. Physicochemical characterization and utilization of Cyperus rotundus starch. Bioresour. Technol., 72: 193-196, (2000).

5. Kapadia, V.H., Naik, V.G., Wadia, M.S., Dev, S. Sesquiterpenoids from Essential oil of Cyperus rotundus. Tetrahedron Lett, 4661: (1967).

6. Trivedi, B., Motl, O., Herout, V., Sorm, F. Composition of the oil from Cyperus rotundus: Structure of patchoulenone. Coil. Czech. Chem. Commun. 29: 1675-1688, (1984). 
7. Sri Ranjani, S., Prince, J. Physico-chemical and Phytochemical study of rhizome of Cyperus rotundus Linn. International Journal of Pharmacology and Pharmaceutical Technology (IJPPT), ISSN: 2277 - 3436, Volume-1, Issue- 2: 42-46, (2012).

8. Dang GK, Parekar RR, Kamat SK, Scindia AM, Rege NN., Antiinflammatory activity of Phyllanthus emblica, Plumbago zeylanica and Cyperus rotundus in acute models of inflammation., Phytother Res. 25(6): 904-8. (2011 Jun). doi: 10.1002/ptr.3345. Epub 2010 Dec 3.

9. Gupta MB, Palit TK, Singh N, Bhargava KP. Pharmacological studies to isolate the active constituents from Cyperus rotundus possessing antiinflammatory, anti-pyretic and analgesic activities. Indian Journal of Medical Research 59: 76-82. (1971).

10. Won-Gil Seo, Hyun-Ock Pae, Gi-Su Oh, Kyu-Yun Chai, Tae-Oh Kwon, Young-Gab Yun, Na-Young Kim, HunTaeg Chung. Inhibitory effects of methanol extract of Cyperus rotundus rhizomes on nitric oxide and superoxide productions by murine macrophage cell line, RAW 264.7 cells, Journal of Ethnopharmacology, Volume 76, Issue 1: Pages 59-64, (June 2001).

11. Weenen $\mathrm{H}$, Nkunya MH, Bray DH, Mwasumbi LB, Kinabo LS, Kilimali VA. Antimalarial activity of Tanzanian medicinal plants. Planta Medica 56: 368370. (1990a).

12. Zhu M, Luk HH, Fung HS, Luk CT. Cytoprotective effects of Cyperus rotundus against ethanol induced gastric ulceration in rats. Phytother. Res. 11: 392-394. (1997).

13. Yu J., Lei G., Cai L. and Zou Y. "Chemical composition of C. rotundus extract ". J. Phytochemistry. 65: 88189. (2004).

14. Zeid abdul-Majid Nima, Majid Sakhi Jabier, Raghidah Ismaeel Wagi,Huda Abd Al-Kareem Hussain,. Extraction, Identification and Antibacterial activity of Cyperus oil from Iraqi C rotundus,. Eng. \& Technology, Vol.26, No.10: (2008).

15. Umerie SC, Ezeuzo HO. Physicochemical characterization and utilization of Cyperus rotundus starch. Bioresour. Technol, 72: 193-196, (2000).

16. Gabriel A. Agbora, Joe A. Vinson, Julianne Sortino, Robert Johnson. Antioxidant and anti-atherogenic activities of three Piper species on atherogenic diet fed hamsters. Experimental and Toxicologic Pathology. 64: 387-391, (2012).

17. Sri Ranjani Sivapalan. International Journal of Scientific and Research Publications, Volume 3, Issue 5: 1-8. (May 2013).
18. Jiao S, Matsuzawa Y, Matsubara K, Kubo M. Abnormalities of plasma lipoproteins in a new genetically obese rat with non insulin dependent diabetes mellitus (wister fatty rat).int $\mathrm{j}$ obes, 17: 461471. (1991).

19. Kyoung M, Dac GK, Ansoo KL, Yeom, Jm Sk, Mi Km et al.anti-atherogenic effects of the aqueous extract of Rhubarb in rats fed an atherogenic diet. The American journal of Chinese medicine, 36(3): 555-568. (2008).

20. K. Gauthaman, T.S. Mohamed Saleem, V. Ravi, Sita Sharan Patel, S. Niranjali Devaraj. Alcoholic Extract of Terminalia Arjuna Protects Rabbit Heart against Ischemic-Reperfusion Injury: Role of Antioxidant Enzymes and Heat Shock Protein. International Journal of Biological, Biomolecular, Agricultural, Food and Biotechnological Engineering, Vol: 2, No: 6, (2008).

21. Priyanga R, Shehani P, GA Sirimal P, Priyadarshani G, Godwin R, Prasad K. medicinal properties of true cinnamon- a systemic review. BMC complementary and alternative med, 13:275, (2013).

22. OECD Obesity Update 2014: www.oecd.org/health/obesity-update.html

23. Woo MN, Bok SH, Lee MK, Kim HJ, Jeon SM, Do GM, Shin. Anti-obesity hypolipidemic effects of a proprietary herb fiber combination (S\&S PWH) in rats fed high-fat diets. J Med Food. 11:169-78. (2008).

24. Lemaure B, Touche A, Zbinden I, Moulin J, Courtios D, Mace K. Administration of Cyperus rotundus tubers extract prevents weight gain in obese zucker rats. Phytother. Res. 21:724-730. (2007).

25. Amat SFC, Taylor MR, Mestroni L, Botto LD, Longo N. Cardiomyopathy carnitine deficiency. Mol Genet Metab, 94:162-6.( 2008).

26. Janssen E, Terzic A, Wieringa B, Dzeja PP. Impaired intracellular energetic communication in muscles from creatine kinase and adenylate kinase (MCK/AK1) double knock-out mice. J Biol Chem, 278:30441-9. (2003).

27. Katzung, B.G.Antihypertensive drugs, in basic and clinical pharmacology. Appleton and lange Stamford, Connecticut, 7th ed.: 154-155. (1998)

28. Fielding BA, Frayn KN: Lipid metabolism. Current Opinion Lipidolology, 11(6):657-659. (2000).

29. Cindik N, Baskin E, Agras PI, Kinik ST, Turan M, Saatci $\mathrm{U}$ : Effect of obesity on inflammatory markers renal functions. Acta Paediatr, 94:1732-7. (2005). 
*Corresponding Author: Muralidhar.S.Talkad*

Email: talkad.murali@rediffmail.com 